\title{
5. Definitions and types of language death
}

\subsection{Introductory notes}

As seen in Chapter 2, language endangerment constitutes a continuum, ranging from the "healthy" phase to the "extinct" phase. Various definitions of language death have been put forward, but there seems to be no consensus. A given language may be considered dead at any point on this continuum. Proposed definitions of language death are examined and a few other possible definitions are suggested in 5.2. Also, language death may be classified in terms of criteria such as cause and speed. Proposed classifications of language death are considered and modifications thereof are proposed in 5.3.

\subsection{Definitions of language death}

It should be noted at the outset that when we use the term "language death", we are using it in a metaphorical sense. According to one view, "languages neither live nor die. They are used or ceased to be used" (Pande 1965: 206).

It may look obvious that "a language dies when it no longer has any speakers" (Campbell 1994: 1960; Romaine 1989: 380; cf. also Thomason 2001: 223). However, as Romaine and Thomason point out, the matter is not easy. For example, like the death of a human being, the death of a language passes through a series of phases, and it is not a straightforward matter to pinpoint the moment (or date or even year) when a given language dies (cf. Elmendorf 1981: 36; Romaine 1989: 380). There are some proposals on the definition of language death, but no consensus seems to exist as to when a particular language is to be considered dead (Brenzinger and Dimmendaal 1992: 3). Most writers do not provide an explicit definition of language death, but they generally seem to maintain the view expounded in [6] below.

Language death may be characterized by a number of factors, the most convenient of which may be the following: (i) locus of language death (Campbell 1994: 1964), such as the community, family, and individual, (ii) degree of proficiency in the language, (iii) use of the language as a vehicle of communication, and (iv) transmission of the language to children. In the following, we shall consider proposed definitions of language death and suggest a few other possible definitions. 
[1] Cessation of development

According to Denison (1977: 14), J. Vachek stated that "a language must be regarded as dead as soon as it stops developing (that is, changing)". It is not certain if there is any language that does not change. As we shall see in Chapter 8, even a dying language undergoes changes. Languages such as Latin and Sanskrit may be considered as those which do not change; they have prescriptive norms from which learners (and speakers?) are not allowed to deviate. However, if there is any new change in the Latin or the Sanskrit of learners, then the language will have to be considered alive, in Vachek's view.

[2] Cessation of transmission of the language in the community as a whole It is possible that a given language is still used as the vehicle of communication by certain members - most likely, elder members - of the community but that it is no longer transmitted to the children of the community as a whole. A language may be considered dead when this happens.

An example of such a definition is the case of Jaru as used in the town of Halls Creek, Western Australia. As of 2002, there are a fair number of old people who speak the language among themselves, but the language is no longer learned by children. According to the definition provided above, Jaru of Halls Creek will have to be considered dead. (But the language is still alive, say, at Ringer Soak Community, an isolated community about $160 \mathrm{~km}$ southeast of Halls Creek, where children speak the language.)

The above is a plausible characterization of language death, although it does not appear to have been seriously proposed before.

[3] Disuse of the language in the community as a whole A language may be considered dead when it ceases to be used as the vehicle of communication in the community as a whole (cf. Brenzinger and Dimmendaal 1992: 3; Sasse 1992a: 18; Thomason 2001: 224). This phase will follow, rather than precede, [2]. That is, it is unlikely that, while a language is transmitted to children, it is no longer used as the vehicle of communication. (Languages like Latin are exceptions. They are taught in school, that is, they are learnt by children but they are not used as the means for communication in the community.)

If such a definition of language death is adopted, there will be many cases where it is difficult to ascertain when a given language died. One example is Warrungu of northeast Australia. When the present writer commenced work on the language in 1971, there were two fluent speakers left: Alf Palmer (Warrungu name: Jinbilnggay) and Alec Collins (Warrungu name: Wulngarra - Peter Sutton, p.c.). They did not live close to each other and had no opportunity to use the language. It appears that they had not actively spoken the language for half a century or even longer. This suggests that Warrungu ceased to be used as the 
vehicle of communication in the early years of the 20th century. However, it is not possible to know exactly when this happened.

[4] Cessation of transmission of the language in all families It is possible that a given language is no longer transmitted to children in the community as a whole, but that it is learned by children in certain - probably a very small number of - families. The language may be considered dead when it is no longer transmitted even in such families, that is, when it is not learned by any children. This definition of language death is possible, although it does not appear to have been seriously considered before.

What percentage of children of a community must learn the language for it to be considered as transmitted in the community as a whole? This is a matter of degree, and it is difficult to decide.

[5] Disuse of the language in all families It is possible that a given language is no longer used as the vehicle of communication in the community as a whole but that it is used as such in certain - probably a very small number of - families. The language may be considered dead when it ceases to be used even in such families. Again, this is a plausible characterization of language death; this characterization also does not appear to have received serious consideration before.

Again, what percentage of families of a community must use the language for it to be considered as used in the community as a whole? This is a matter of degree, and it is difficult to decide.

[6] Death of native speakers or fluent speakers

(a) Fluent speakers. A language may be considered dead when its last fluent speaker passes away. This view is held, for instance, by Elmendorf (1981: 36) and, no doubt, by many others, although this is not always stated explicitly.

An example of language death in this definition is provided by Warrungu of northeast Australia, mentioned in [3] above. It became extinct in 1981, when the last fluent speaker (Alf Palmer) passed away.

It should be noted, however, that this definition, too, is not free from problems. It is difficult to define "fluent speaker". As we shall see in 9.4.1.1, fluency is a matter of degree. What degree of proficiency does a speaker require in order to be considered as a fluent speaker? This is a very difficult issue. (Alf Palmer's proficiency in Warrungu will be described in 8.3 and 9.4.1.1-(b-i).)

(b) Native speakers. A language may be considered dead when its last native speaker passes away. This view is held, for instance, by Hill (1983: 260) and by the anonymous author of the article "Man, Isle of: Language Situation" on the Manx language, in Asher (ed.) 1994, Encyclopedia of Language and Linguistics, Vol. 5: 2357, Oxford: Pergamon Press. 
This definition, too, has its own problems. First, the concept of native speaker may appear to be a straightforward matter. However, like other concepts in linguistics, it is extremely controversial; see Davies (1994) and Mc Laughlin and Sall (2001: 202), for instance. Davies (1994: 2723) lists six ways to characterize a native speaker, and one of them concerns the first language a speaker acquires. Second, in fieldwork situations it is not always easy to find out what a given speaker's first language is.

There is a further discussion of first language speakers and native speakers in 9.4.2-[2].

[7] "Rememberers"

Knab (1980: 232) employs the term "rememberer" to refer to a person who "passively remembers fragments of the language". It is often the case that fragments of a language survive long after the death of the last fluent or native speaker of the language. See Beeler (1977: 45) on Esselen of California, and Crowley and Dixon (1981: 398) on Tasmanian languages of Australia. In 1972, Terry Crowley tape-recorded five words and one sentence from two part-Tasmanians: Mrs. Heffernan and Mrs. Mundy (Crowley and Dixon 1981: 397-398). Another example from Australia: in 1974, the present writer recorded Reggie Palm Island, who was one of the few surviving members of the original group of Palm Island, and who was probably the last speaker of the Buluguyban language of that island. The author was able to obtain only about 40 words, a dozen phrases, and one story (narrated in English), about the travel of Carpet Snake. (See Tsunoda 1996b.)

Now, another definition of language death is possible: a language becomes dead when the last rememberer passes away. Again, this definition does not appear to have been considered before.

[8] Second language speakers

Two types of second language speaker may be recognized: (i) second language speakers (in a narrow sense): those who speak a second language (in addition to their first language; see D.A. Wilkins 1994: 3715), and (ii) another-group language speakers: those who speak the language of another group (in addition to the language of their own group; see Bradley 1989: 38, Evans 2001: 256, 273, Fishman 1991: 397, and Hinton 1994: 24).

Clearly, second language speakers of the type (a) are not native speakers of the second language. Also, they are likely - though not always - not to be fluent speakers thereof. Another-group language speakers may well be fluent speakers of the language of another group. (Thus, there are Japanese people who were born in Australia and who speak English fluently.) On the whole, however, they will be unlikely to be fluent speakers of their second language. 
The sense (b) "another-group language speakers" seems more useful than the sense (a) in discussions of language endangerment. An example of the sense (b) comes from Australia. In the 1960s, while working with two speakers of the Kalkatungu language of northwest Queensland, Blake found that these two speakers also knew some Yalarnnga, a language adjacent to Kalkatungu (Blake 1971: 12-33). It is possible to say - in line with [6] - that the Yalarnnga language died when the last fluent or native speaker of the Yalarnnga group passed away. But it is also possible to say that the language became extinct when its last second language speaker passed away. Again, this is a plausible characterization of language death, although it does not appear to have been seriously proposed before.

[9] Researchers

There are a large number of researchers who have worked on endangered languages and who have a varying degree of command of thereof. It is possible to say that a given language is alive while a relevant researcher is alive, and that it becomes extinct when he/she passes away.

To take another example from Australia, the last fluent speaker of Warrungu passed away in 1981 (see [6] above). According to the view put forward in (a) of [6], Warrungu became extinct in that year. However, there is still one researcher alive, viz. the present writer, who knows some Warrungu, and who is able to write technical papers on it. It is possible to say that Warrungu is still alive and not dead. On this view, the present writer is the last speaker of Warrungu.

Such a view may sound absurd and, indeed, researchers have not considered such a view seriously - except for Golla (2001: 176-177). Nonetheless, it is worth considering seriously for at least three reasons, given below.

First, it may be objected that the present writer is not of Warrungu descent. Should factors such as race (cf. Davies 1994: 2721) or descent be taken into account when considering the membership of speakers of a given language? The answer is "No", and race or descent constitutes no ground for denying the present writer the status of a Warrungu speaker.

Second, it may be objected that the present writer learned Warrungu as an adult. However, many people learn Maaori, for example, as adults (cf. Nicholson 1990; and also 11.5.2 below). If they are considered as speakers of Maaori, then there is no reason why the present speaker should not be regarded as a speaker of Warrungu.

Third, the present writer is more proficient in Warrungu than, for example, Reggie Palm Island was in Buluguyban (mentioned in [7] above). If Reggie Palm Island is considered a speaker of Buluguyban, then again there 
is no reason why the present writer should not be classified as a speaker of Warrungu.

These three arguments will show convincingly that it is not absurd to state that a language is alive as long as the relevant researcher is alive. If such a view is adopted, no doubt there will be many languages whose last speakers are researchers. For example, Gavan Breen has worked with the last speakers of dozens of Australian Aboriginal languages and he will be considered the last speaker of these numerous languages.

What can remain after the last fluent or native speaker passes away? We have seen three kinds: rememberers, second language speakers, and researchers. There are still more that may survive and a language may be said to be alive as long as any one of them is preserved.

[10] Records of the language: books, tapes, and CDs

It may be possible to say a language is alive as long as its record is preserved. Denison (1977: 13) suggests the possibility of such a view, although he does not seem to subscribe to it, while Brenzinger (1998a: 99) seems to hold this view. Types of such record will include dictionaries, grammars, texts/stories, as well as audio- and video-recorded materials, and, more recently, CDs. In passing, we note that there is a possibility (and this has been observed) that some members of the community mistakenly believe that their language is "OK" as long as their language is recorded on CDs and that consequently they do not make serious efforts to transmit the language.

[11] Substratum, e.g. vocabulary

A language may leave traces of its earlier presence in the form of a substratum, especially in the lexicon (Dimmendaal 1989: 25; Sasse 1992a: 18). Examples follow. Many place names of Ainu origin are found in the northern part of Japan (Tamura 2000a: 269). African pygmies retain a trace (and the only trace) of their language in their botanic terminology (Dimmendaal 1989: 28). In a large area of eastern Australia where no Aboriginal language is spoken any longer, there are places called Yamba or the like; see Tsunoda (1996b). (The word yam$b a$ means 'camp, ground' in Warrungu and many other languages.)

It is possible to say that a language is alive as long as it survives in place names or the like (Veri Farina, p.c.) As we shall see in Chapter 10, a given group's language is considered to be a very central part of their cultural heritage and ethnic identity, and the death of their language is an irrecoverable loss to the group. To state that their language survives in, say, place names is one of the ways to maintain their heritage and identity in terms of language.

Hawaii seems to be exceptional in that perhaps all (or almost all) place names - of islands, cities, towns, and streets, e.g. Honolulu - are taken from the local aboriginal language. This is in sharp contrast with, say, Australia, where it 
is very uncommon to come across place names taken from the local language, with a small number of exceptions such as Yamba mentioned above. If a language is considered alive as long as it survives in place names or the like, then the Hawaiian language will be regarded fully viable, and certainly far more alive than any Australian Aboriginal language.

Apart from the phenomena discussed above, a language may be said to leave residues in the form of a ritual language, a secret language, a professional jargon (Sasse 1992a: 18), a pidgin, or a creole. (Use of a language for secrecy will be exemplified in 7.2.2, while pidgins and creoles will be compared with endangered languages in 8.4.5.2.) Naturally, there must have been numerous languages that have disappeared leaving no trace behind.

We have seen various definitions of language death. As will be obvious, it is difficult to use this term in a precise sense. First, it is difficult to define it precisely. Second, often the sources consulted do not provide an explicit definition of language death.

\subsection{Types of language death}

\subsubsection{Introduction}

There have been attempts to typologize language death. Unfortunately, however, they do not always distinguish different types of criteria and, consequently, the classifications proposed are sometimes inconsistent and confusing. Thus, Campbell and Muntzel (1989: 182-186) list four types of language death, one of which is "sudden death". They define it as the "case where a language abruptly disappears because almost all of its speakers suddenly die or are killed". Note that this definition refers to both the speed and the cause of the language death.

In examining types of language death, we need to distinguish between (i) the cause and (ii) the speed of a given language death. Language death has also been classified in terms of (iii) the register (or style) involved in a given instance of language death. In the following we shall consider various types of language death in terms of these three criteria.

\subsubsection{Classification in terms of cause}

In terms of the cause, language death may be classified as follows: (i) language death due to the death of the population, and (ii) language death due to language shift (also known as language replacement and language displacement: Brenz- 
inger 1997: 273; Fishman 1964: 32, 1972: 110). (For this classification, see Dorian 1981, 2001b: 8357, Elmendorf 1981: 37, Hill 1983: 260, Hoenigswald 1989: 347, and Schmidt 1985b: 3-4.)

Almost all of the proposed classifications of language death refer to causes. (Causes of language death will be further discussed in Chapter 6.) It seems that language death of type (ii) is much more common than that of type (i). We shall consider each of the two types.

[1] Language death due to death of the population A language may become extinct due to the death of the entire population that speaks it. The causes for this type of death cited in the literature include the following: warfare, genocide, extermination, volcanic eruptions, tsunami and epidemics.

For this type of language death at least three terms have been proposed: (i) language murder, i.e. physical liquidation (genocide) of all speakers of a language (Dressler and Wodak-Leodolter 1977a: 5), (ii) biological language death, referring to language death caused by rapid population collapse (Hill 1983: 260261), and (iii) glottocide, referring to the destruction of the language of a group due to causes such as genocide (Matisoff 1991: 201). In the following, we shall adopt the term "glottocide" to refer to the type of language death caused by the death of the population.

As noted above, glottocide seems to be much less common than language death caused by language shift (cf. Brenzinger and Dimmendaal 1992: 3; Campbell and Muntzel 1989: 184-185; Elmendorf 1981: 37; Hill 1983: 261; and Matisoff 1991: 201). Nonetheless, there have been many instances of glottocide, as mentioned in Chapter 3, e.g. 3.5 through 3.7. Additional examples follow.

Brenzinger and Dimmendaal (1992: 3) state that in Africa glottocide has been reported within the Khoisan language family. Matisoff (1991: 201) notes that the people of the once-powerful empire of the Xixia (or Tangut), on the Western fringes of China, in the Qinghai/Tibet/Sichuan region, were annihilated by Kubilai Khan's Mongols in the closing years of the thirteenth century. Dixon (1991a: 241) reports an instance of glottocide caused by a volcanic eruption on the island of Sumbawa, Indonesia, in 1815, which resulted in the death of all speakers of the Tamboran language. This language is known only from a short word-list in Sir Thomas Stanford [sic] Raffles' History of Java (1817). (Yeong Kwong Leong, p.c., has pointed out that the correct spelling is Stamford, with $m$ rather than $n$.)

[2] Language death due to language shift This occurs when a given language dies because its speakers shift to another language. The difference between glottocide and language shift can be shown as in Figure 5-1. The arrowed line indicates the existence of speakers. 
glottocide

language shift $\stackrel{\text { language } A \quad \stackrel{\text { language } B}{\longrightarrow}}{\longrightarrow}$

Figure 5-1. Glottocide and language shift

The language A is variously called, e.g. abandoned language (Sasse 1992a: 13; Thomason and Kaufman 1988: 100), disappearing language (Brenzinger 1997: 273), fading language (Brenzinger 1997: 283), receding language (Brenzinger 1997: 274; Dorian 1973: 413; Fishman 1991: 23), and recessive language (Dorian 1999a: 101). Similarly, the language B is termed, e.g. conquering language (Bloomfield 1927: 437; Thomason 2001: 223; Thomason and Kaufman 1988: 101), expanding language (Dorian 1999a: 99), replacing language (Brenzinger 1997: 273; Elmendorf 1981: 37), spreading language (Brenzinger 1997: 274), and target language (Dorian 1999a: 99; Sasse 1992a: 13; Thomason and Kaufman 1988: 111).

Broadly speaking, in a language contact situation, which does not necessarily involve language shift, one language is often known as minority language (Amery 2000: 217; Brenzinger 1997: 275; Dorian 1986b: 73), dominated language (Abbi 1995: 178), non-dominant language (Dorian 1986b: 80) or nonmainstream language (Dorian 1986b: 82), and the other language as majority language (Amery 2000: 217), dominant language (Abbi 1995: 178; Brenzinger 1997: 274; Dorian 1986b: 72; Fishman 1964: 44; Haugen 1972: 336; Thomason 2001: 225; Thomason and Kaufman 1988: 100) or superordinate language (Dorian 1994a: 675).

\subsubsection{Classification in terms of speed}

In terms of speed, language death may be classified as follows: (i) instant death, or sudden death, and (ii) gradual death, or slow death.

Various terms apparently relating to the speed have been employed, e.g. instant language death, sudden death, radical death, slow language death, gradual death (Campbell 1994: 1960-1961; Campbell and Muntzel 1989: 182-184; Dressler and Wodak-Leodolter 1977a: 5; Matisoff 1991: 201). Literally, these terms concern the speed only, but reference to the cause sneaks into their definitions. As an example, see Campbell and Muntzel's definition of sudden death, cited in 5.3.1. The present work distinguishes between the speed and the cause. 
Instant or sudden death seems uncommon (Dressler and Wodak-Leodolter 1977a: 5; Matisoff 1991: 201), while gradual or slow death seems common.

To be precise, however, "sudden/instant" and "gradual/slow" constitute a continuum, and whether a given instance of language death is sudden or slow is a matter of subjective judgement. What length of time should be considered sudden/instant? One or two years? Five years? Ten years? One generation? One century? The length of ten years may be plausibly considered gradual/ slow. However, five years may be considered sudden, given the length of time a child needs to acquire a language. (The writer owes this observation to Toshinari Yamashita.) Furthermore, since a language is transmitted from adults to children, one generation may be considered sudden/instant. If a language disappears within one generation, this disappearance will have to be considered sudden/instant. (Dixon 1991a: 236 adopts this view.) Even one century may be considered sudden/instant. Take, for example, the death of Tasmanian languages. It was 73 years from the first European contact in 1803 to the death of the last full-blooded Tasmanian in 1876 (Crowley and Dixon 1981: 396), and this is cited as an instance of sudden death by Campbell (1994: 1960) and by Campbell and Muntzel (1989: 182). Naturally, however, it is also possible to say that this instance, which continued for three quarters of a century, is gradual/slow.

As will be clear now, it is difficult to say what length of time should be considered sudden/instant and what length of time should be considered gradual/slow. Also, the sources consulted do not comment on this issue. The case of Xixia (or Tangut) (caused by the annihilation of the population) and that of Tamboran (due to a volcanic eruption), cited in 5.3.2, are clearly instances of sudden language death, but such unequivocal instances are hard to find.

\subsubsection{Combination of cause and speed}

Cause and speed are independent of each other. Combination of these two criteria yields the following classification of language death: (i) sudden glottocide, (ii) gradual glottocide, (iii) sudden language shift, and (iv) gradual language shift. We shall look at each of the four types. As noted in 5.3.2, most instances of language death seem to be caused by language shift, and glottocide appears to be uncommon. Also, as mentioned in 5.3.3, gradual or slow death seems common, while instant or sudden death seems uncommon. That is, the most common type of language death is the one caused by gradual language shift (Campbell 1994: 1960-1961; Campbell and Muntzel 1989: 184-185). 
[1] Sudden glottocide happens when a population suddenly dies out. As stated above, this type does not seem common. Clear examples are the case of Xixia (or Tangut) and that of Tamboran (5.3.2). Two additional examples are given in [3] below.

[2] Gradual glottocide. In this type, the population of a group is reduced gradually, until the point where the last member of the group is also the last speaker of the language. This type seems uncommon, but depending on the definition of language death and the definition of "gradual", the case of Tasmanian languages (5.2-[7] and 5.3.3) may be considered as an instance of this type. Also, some of the instances reported by Swadesh (1948) and by Hill (1983: 260261) may be of this type.

[3] Sudden language shift happens when a population shifts to another language suddenly. Thus, Campbell and Muntzel (1989: 183) and Campbell (1994: 1960) report: "in El Salvador, due to a 1932 massacre in which thousands of Indians were killed, Cacaopera and Lenca soon became extinct, and Pipil became quite moribund. Many simply stopped speaking their native languages as a survival strategy", i.e. "to avoid being identified as Indians". The cases of Cacaopera and Lenca are instances of sudden glottocide, while that of Pipil appears to be an instance of sudden language shift. Another, possible instance is a phenomenon that Dorian termed "tip" (Colette Grinevald, p.c.). "Tip" refers to "abrupt transmission failure" (Dorian 1989a: 9): "a language which has been demographically highly stable for several centuries may experience a sudden 'tip', after which the demographic tide flows strongly in favor of some other language" (Dorian 1981: 51). For accounts of tips, see Dorian $(1981,1986 b)$ on Scottish Gaelic of East Sutherland, Scotland; Mertz (1989) on Scottish Gaelic of Cape Breton, Nova Scotia, Canada; and Rouchdy (1989a) on Egyptian Nubian. In each of these three instances, a bilingual phase seems to have preceded the "tip". It is not known if the same was true of the Pipil situation.

[4] Gradual language shift happens in a language contact situation when a group of people shift to another language slowly. It goes through an obsolescing state which has the following characteristics (Campbell 1994: 1961; Campbell and Muntzel 1989: 185; Dorian 1981: 4, 2001b: 8357; Hoenigswald 1989: 347):

(a) intermediate stage of bilingualism, in which the language is gradually replaced by the dominant language in an increasing number of contexts, and;

(b) proficiency continuum, in which different speakers exhibit different degrees of proficiency, determined principally by age (but also by attitude and other factors); typically older speakers are the more proficient and younger speakers are the less proficient (or not proficient at all) in the receding language. 
As noted above, gradual language shift is the most common among the four types under consideration and this type has been the central concern in studies of language endangerment, as will be the case in the ensuing chapters. In particular, bilingualism in relation to language shift will be discussed in 7.3.3, and a proficiency continuum will be illustrated in Chapter 8 (Figure $8-1$ and most of the ensuing figures).

Note that sudden glottocide "leaves, by definition, no obsolescing state to investigate structurally" (Campbell and Muntzel 1989: 182-183), since the population dies out suddenly.

Incidentally, Campbell (1994: 1960) and Campbell and Muntzel (1989: 182) cite Tasmanian as a case with no obsolescing state to investigate structurally. However, it seems likely that Tasmanian languages did have an obsolescing state during the 73 years of their decline to death (5.3.3). There were also "rememberers" whose language exhibited an obsolescing state, which Terry Crowley recorded (5.2-[7]).

\subsubsection{Classification in terms of register involved in language death}

This classification concerns registers or styles, and two types may be recognized (Campbell 1994: 1960-1961; Campbell and Muntzel 1989: 185; Hill 1983: 260): (i) the top-down pattern, and (ii) the bottom-up pattern.

The top-down pattern seems much more common than the bottom-up pattern. This is noted by Hill (1983: 260) regarding North American languages. An example from Australia is the following. Alf Palmer (mentioned in 5.2-[3]) knew that Warrungu used to have two styles: ordinary and avoidance styles. (The latter was used, for instance, between taboo relations, such as mother-inlaw and son-in-law.) Although he had an excellent command of the ordinary style, he admitted that he did not know the avoidance style. That is, the avoidance style had disappeared, but the ordinary style remained. This is clearly an instance of the top-down pattern. (The case of the Warrungu avoidance style will be further discussed in 8.3.)

The opposite pattern, i.e. bottom-up (referred to as "bottom-to-top death" by Campbell and Muntzel 1989: 185), is called Latinate pattern by Hill (1983: 260). It is "exemplified by the famous case of Latin, where the repertoire of registers suffers attrition from the bottom up, being abandoned first in the family vernacular and surviving ultimately only in the most elevated contexts" (Hill 1983: 260).

Clearly, this pattern is uncommon. Hill (1983: 260) mentions two possible instances, but does not give concrete examples. Campbell and Muntzel (1989: 
185 ) and Campbell (1994: 1960-1961) cite three possible examples, involving prayers, songs, and chants. But Campbell and Muntzel (1989: 185) admit that they have no perfect examples of this type.

To be precise, however, the examples of the bottom-up pattern cited above are not really parallel to those of the top-down pattern. In the top-down pattern, the speakers would often have a good - or even full - command of the "low" style (cf. Alf Palmer) and they might even use it for daily communication. In contrast, in the instances of the bottom-up pattern, particularly in those cited by Campbell and Muntzel, the speakers would not have a good command of the "high" style, and surely they would not use it for daily communication. That is, the bottom-up pattern is not on a par with the top-down pattern.

\subsection{Summary of Chapter 5}

The viability, or conversely endangerment, of languages constitutes a continuum, and a given language may be considered dead at any point on this continuum. There are various definitions (including the ones suggested by the present work) of language death. There seems to be no clear consensus, although many linguists seem to implicitly hold the view that a language becomes extinct when it last fluent or native speakers pass away. It is useful to classify language death in terms of the cause and speed. In this classification, the most common type of language death is the one that is caused by language shift and that takes place slowly/gradually. This type of language death is the main focus of most works on language endangerment, and also of the chapters that follow. 